\title{
O MITO DO OBJETIVISMO: ALGUMAS IMPLICAÇÕES PARA O DISCURSO
}

Fátima Cristina Dória Ramirez dos SANTOS ${ }^{1}$

O objetivo deste artigo é apresentar um panorama geral do fenômeno chamado na cultura ocidental de objetivismo e discutir algumas de suas implicações para o discurso, tomando como base, principalmente, teorias recentes da visão de metáfora conceitual. É interessante observar como isto se dá de maneira tão desapercebida por muitos, inclusive por professores e alunos. Para tal objetivo, faz-se necessário um exame do chamado mito do objetivismo conforme George Lakoff e Mark Johnson (2002). Sendo o objetivismo tão influente em nosso meio, torna-se fundamental a sua compreensão para um melhor entendimento de suas manifestações no discurso. Assim, pretende-se apresentar o objetivismo e seus pressupostos, bem como seus desdobramentos, através dos conceitos estabelecidos por esses autores, dentre outros.

A busca da verdade e do conhecimento sempre fora uma constante na vida do homem ocidental. Apesar de inúmeras tentativas infrutíferas de se chegar a uma conclusão, essa mesma busca pela verdade tem provocado discussões infindáveis, desde os antigos gregos até hoje, e acredito que ainda o fará por muito tempo. Como Lakoff e Johnson (2002) afirmam, a questão da verdade absoluta, principalmente para aqueles pertencentes ao meio científico, ainda é experienciada como um dogma. Em outras palavras, pode-se dizer que, embora não se tenha certeza da inteira verdade, muitas pessoas amedrontam-se diante de quaisquer questões em que tenham que se 'render' a um certo subjetivismo. Eles argumentam que "a verdade é sempre relativa a um sistema conceptual, que qualquer sistema conceptual humano é, em grande parte, metafórico por natureza

1. Professora da UNESA, UNISUAM, SEE e SME. 
e, portanto, que não há verdade inteiramente objetiva, incondicional ou absoluta" (LAKOFF e JOHNSON: 2002, p. 293).

De acordo com Lakoff e Johnson (2002), tanto a aceitação total do dogma da verdade quanto de uma exclusiva individualidade, são visões bastante equivocadas que constituem o mito do objetivismo e subjetivismo respectivamente. E, embora equivocadas, pode-se depreender que, na cultura ocidental, há apenas estas duas alternativas: a crença numa verdade absoluta ou a crença na possibilidade de se fazer o mundo a sua própria imagem.

Os autores esclarecem que tanto as metáforas quanto os mitos fazem parte de todas as culturas, e que, portanto, se fazem necessários à medida que as pessoas ordenam suas vidas e dão sentido ao que está em volta delas. Porém, é interessante observar que o mito do objetivismo não só desconhece seus próprios mitos como negligencia a metáfora na sua busca desenfreada pela verdade. Lakoff e Johnson (2002) apresentam uma série de crenças que constituem o mito do objetivismo:

1. “O mundo é constituído por objetos". Os objetos possuem propriedades que existem independentemente de quem os experiencia. Uma pedra, por exemplo, é dura e existe como um objeto separado ainda que não houvesse mais ninguém no universo;

2. "Adquirimos nosso conhecimento do mundo experienciando os objetos e chegando a saber que propriedades os objetos têm e como eles se relacionam entre si";

3. "Compreendemos os objetos de nosso mundo em termos de categorias e de conceitos. Estas categorias e conceitos correspondem às propriedades que os objetos têm neles mesmos e às relações deles com outros objetos". Por exemplo, temos a palavra "pedra" que corresponde ao conceito "PEDRA" e, considerando-se uma determinada pedra, pode-se saber se a mesma se inclui na categoria PEDRA e não em outra; 
4. "Há uma realidade objetiva e podemos dizer coisas que são objetivamente, absolutamente e incondicionalmente verdadeiras e falsas sobre ela". De acordo com a concepção objetivista, o sentido é objetivo e existe independentemente do entendimento humano. Ele não é jamais aquilo que alguém entende sobre alguma coisa, pois o sentido objetivo exclui quaisquer aspectos considerados subjetivos, isto é, contexto, cultura, emoções ou modo de compreensão particular. Ao contrário, deve expressar, através da ciência, explicações corretas e definitivas e por isso progredir continuamente;

5. "As palavras têm significados fixos, isto é, nossa linguagem expressa os conceitos e as categorias em termos dos quais pensamos". Assim, ao julgarmos se premissas são falsas ou verdadeiras, é necessário que saibamos escolher as palavras para que as usemos de maneira direta $\mathrm{e}$ objetiva. Conseqüentemente, podemos nos referir com precisão ao mundo externo, já que a linguagem objetiva reflete o mundo como ele é;

6. "As pessoas podem ser objetivistas e podem falar objetivamente, mas só o conseguem se utilizarem uma linguagem que seja clara e precisamente definida, direta e sem ambigüidade e que corresponda à realidade";

7. "A metáfora e os outros tipos de linguagem poética, imaginativa, retórica ou figurada podem sempre ser evitados ao se falar objetivamente, e deveriam ser evitados, pois seus significados não são claros nem precisos e não correspondem de um modo claro à realidade";

8. "Ser objetivo é geralmente uma coisa boa. Somente o saber objetivo é realmente um saber". Acredita-se que através da objetividade podemos compreender o mundo mais claramente, romper com preconceitos pessoais e sermos mais justos;

9. "Ser objetivo é ser racional; ser subjetivo é ser irracional e se deixar dominar pelas emoções";

10. "A subjetividade pode ser perigosa, pois ela pode provocar uma 
perda de contato com a realidade". Como a subjetividade considera um ponto de vista pessoal, ela pode ser injusta.

Também Ortony (1993) argumenta que a descrição e explicação da nossa realidade física constituem a pressuposição central de nossa cultura. De acordo com o autor, a ciência caracteriza-se pela precisão e ausência de ambigüidade, de tal forma que a linguagem utilizada no seu domínio deve, necessariamente, ser precisa e não tendenciosa; ou seja, literal. Esse tipo de linguagem era privilegiada no âmbito da filosofia ocidental do início do século XX. Ortony (1993) acrescenta que esta crença culminou com os pressupostos do positivismo lógico, o qual influenciou inúmeros filósofos e cientistas num passado recente.

Cabe aqui também citar Pedro Demo:

A obsessão pela objetividade (da realidade) e neutralidade (do sujeito) no paradigma modernista da ciência sempre foi marca ostensiva, correspondendo menos ao que seria a realidade, do que às expectativas dos métodos de análise. $\mathrm{O}$ pós-modernismo colocou em xeque tais crenças porque são apenas crenças. Acreditamos piamente que vemos a realidade assim como ela é, embora a vejamos assim como podemos. (PEDRO DEMO: 2001, p. 23)

Segundo Hessen, (2000) o elemento decisivo na relação de conhecimento é o objeto. É ele que determina o sujeito e este deve ajustar-se àquele. Para tal, basta que o objeto se coloque diante da consciência como algo pronto e determinado em si mesmo. Hessen afirma que Platão foi o pioneiro defensor de tais premissas. Para este, as idéias eram realidades objetivamente dadas. Assim como os objetos do mundo sensível podem ser percebidos, os objetos do mundo supra-sensível (idéias) podem ser contemplados. Conseqüentemente, de acordo com este filósofo, este mundo das idéias torna-se a base sobre a qual se assenta o conhecimento.

Porém, não é somente no âmbito acadêmico que o mito do obje- 
tivismo exerce influência. Em sua dissertação de mestrado, Cristiane Cerdera (2002) cita, por exemplo, que em uma entrevista à revista Veja (Janeiro/2002), o psicólogo Michael Shermer, diretor de uma ONG denominada Sociedade dos Céticos, deixa claro que a ciência seria o único campo do saber humano passível de eliminar erros com facilidade. Este fato, embora isolado, parece revelar como as pessoas encaram o papel da ciência na sociedade. Ou seja, o mito parece ser parte integrante do "inconsciente coletivo" já há bastante tempo.

\section{Considerações sobre o mito do subjetivismo na cultura ocidental}

Embora este trabalho focalize primordialmente a questão do mito do objetivismo, faz-se necessário, para um maior entendimento, uma breve discussão a respeito do mito do subjetivismo.

Com o advento da Revolução Industrial e do progresso tecnológico da ciência, nossa sociedade sofreu um processo desumanizador. Como forma de reagir a essa realidade, artistas, poetas e filósofos desenvolveram o que chamamos de tradição romântica. A função principal do Romantismo seria reforçar a dicotomia entre os binômios razão e verdade/arte e imaginação. No entanto, para os contrários ao Romantismo, a racionalidade continuou a ser objetiva, assim como para os objetivistas. Para estes a subjetividade é considerada potencialmente perigosa, pois só o conhecimento objetivo pode levar à verdade.

Como o mito do objetivismo, o subjetivismo também apresenta crenças enraizadas na cultura ocidental. Segundo Lakoff e Johnson (2002) a crença mais arraigada seria a nossa capacidade de usar sentidos e intuições no dia a dia. Muitos acreditam que a intuição pode ser o melhor guia para nossas ações. Seguindo esta perspectiva, a moral, nossos sentimentos e espiritualidade representam os aspectos mais importantes da vida. A arte e a poesia são instrumentos valiosos já que transcen- 
dem a racionalidade e objetividade através dos sentimentos e percepções. E, em relação à nossa compreensão pessoal, os significados das palavras baseados no senso comum não são suficientes.

Para o subjetivismo, o objetivismo também é considerado perigoso já que despreza o que aquele considera altamente significativo. A objetividade é compreendida como não-humana e injusta pelo fato de ignorar o que é mais relevante e valorizar o universal e impessoal. Os subjetivistas acreditam que a ciência não tem real valor no universo humano, pois não é capaz de conduzir o homem ao mundo interior.

\section{A Síntese Experiencialista}

Tratando-se do mito do objetivismo e do subjetivismo, não se poderia deixar de mencionar a chamada 'Síntese Experiencialista'. Lakoff e Johnson (2002) defendem uma proposta conciliadora entre correntes aparentemente opostas. O que é mais interessante e inovador é que os autores propõem a metáfora como o instrumento para se realizar essa síntese. Para eles, as visões objetivista e subjetivista estão igualmente equivocadas e se anulam mutuamente. Por isso, eles propõem uma terceira alternativa: a síntese experiencialista. Esta seria a ponte de união entre as duas visões opostas, a partir da metáfora. Esta é considerada como uma espécie de racionalidade imaginativa, cuja função seria nos ajudar a "compreender parcialmente o que não pode ser compreendido totalmente: nossos sentimentos, experiências estéticas, práticas morais e consciência espiritual". (LAKOFF e JOHNSON: 2002,: p.303) Através de uma construção cognitiva do real via metáfora, os autores não consideram o sujeito individual, mas sugerem um sujeito que se constitui a partir de metáforas geradas no âmbito de uma cultura.

O que Lakoff e Johnson trazem de inovação é o fato de que não se trata simplesmente da inexistência de verdades, mas que a verdade é re- 
lativa ao nosso sistema conceptual. Ela é construída e usualmente testada por nossas experiências nas interações com outras pessoas de nosso ambiente físico e cultural. Então, embora não exista objetividade absoluta, pode existir um tipo de objetividade relativa ao sistema conceptual de uma cultura. Indubitavelmente, não seria tarefa fácil descartar nossos 'vieses individuais' para se obter o êxito desejado e o equilíbrio perfeito. Também seria exagero dizer que devemos ser movidos puramente por nossas intuições tão subjetivas.

Em relação à questão de justiça, os autores argumentam que valores culturais não representam a última instância, já que normalmente existem diferentes tipos de modelos culturais de justiça. Alem disso, os valores culturais geralmente se modificam com o tempo e a história, o que complica um pouco esta avaliação.

Dessa forma, acredita-se que tanto o mito do objetivismo quanto do subjetivismo fornecem implicações para teorias do conhecimento e pensamento do saber científico. Pode-se exemplificar melhor fazendo uma breve retrospectiva histórica desta área.

\section{Uma Retrospectiva Histórica}

Os sofistas eram extremamente céticos em relação à descoberta da verdade. Já os antigos gregos acreditavam na dimensão transcendental do Ser. (ALMEIDA: 1997, p.13) Por outro lado, para Platão o conhecimento consistia na apreensão dos aspectos imutáveis da existência. Sua filosofia eleva o ideal socrático, o qual tem como base a reflexão e o saber. Já Aristóteles, considerava o conhecimento científico e seu objeto, o ser, como alvo principal. Ao contrário de Platão, argumentava que o verdadeiro conhecimento advinha de informações fornecidas por todos os graus, o que não provocaria ruptura entre o conhecimento sensível e o intelectual necessariamente (CHAUÍ, 1999). 
Dentre outros, John Locke destacou-se como iniciador da filosofia do conhecimento. Assim como Aristóteles, também reconhecia graus diferentes de conhecimento, desde a experiência dos sentidos (as sensações) até o pensamento, negando com isso o inatismo. Este sistema filosófico ficou conhecido como empirismo. Entretanto, embora diferentemente de Platão, as concepções de Locke também são de cunho objetivista, uma vez que, como Lakoff e Johnson ressaltam, o filósofo desprezou a linguagem figurativa, considerando-a inimiga da verdade: "O medo da metáfora e da retórica na tradição empirista é o medo do subjetivismo - medo da emoção e da imaginação" (LAKOFF e JOHNSON: 2002, p.300).

Outro filósofo que combateu o subjetivismo foi Descartes. Ele acreditava que era totalmente possível distinguir o verdadeiro do falso na ciência e na filosofia. A razão seria a ferramenta primordial a guiar o homem. Assim como Platão, para ele as idéias eram inatas, auto-evidentes, verdadeiras, claras e simples. Os grandes responsáveis por nossos erros e enganos, segundo Descartes, seriam a cultura, o costume e o exemplo. O que se tem no cerne do sistema cartesiano "é a razão individual contra a cultura" (GELLNER: 1992, p.21). Apesar de ter influenciado bastante o pensamento científico, este sistema começou a sofrer abalos por volta do final do século XVII, quando o italiano Vico propôs uma alternativa para o problema do conhecimento.

Vico (1999) não só questionou as bases do cartesianismo como foi um dos primeiros filósofos a ressaltar a função da metáfora na construção do conhecimento. Examinando os princípios das ciências "duras" , como a física ou matemática, concluiu que há uma enorme divergência entre o que Descartes define como 'certo' e 'verdadeiro'. A física, por exemplo, representa ordem da certeza (real), mas não da verdade. A matemática, puramente inventada e convencionalizada pelo homem, 
não oferece conhecimento do real. Dessa maneira, seria impossível ao homem obter um conhecimento verdadeiro sobre a natureza das coisas, pois ele não é o criador dela e portanto, a desconhece.

Em relação à metáfora, Vico a considera o instrumento principal na apreensão do mundo. Ele enfatiza o aspecto coletivo (e não individual) do pensamento metafórico. Opostamente a Descartes, ele constrói sua ciência como uma história das idéias, costumes e feitos do gênero humano (VICO, 1999). Também contrariamente ao pensamento aristotélico, Vico reconhece a metáfora como indispensável à cognição e não como mero recurso retórico. Assim, ele procurou oferecer uma inovadora alternativa para o problema do conhecimento e da verdade.

Ainda outros filósofos e teóricos continuaram a oferecer caminhos alternativos. Como exemplo pode-se citar o pós-estruturalismo, que apresentou uma reação contra o estruturalismo dos anos 50 e 60 e que de acordo com Peters (2000, p.51) podem ser resumidos assim: uma perspectiva antiepistemiológica; um anti-essencialismo; um antirealismo em termos de significado e referência; um antifundacionalismo; uma suspeita em relação a argumentos e pontos de vista transcendentais; a rejeição de descrições canônicas e de vocabulários finais.

Também o filósofo americano Richard Rorty (1998) questionou as pressuposições da epistemologia moderna. Ele nos convidou a abandonar a distinção aparência/realidade das coisas, uma vez que desconhecemos a realidade em si mesma. Segundo o mesmo, a verdade não deve ser nosso objetivo último, pois:

Um objetivo é algo sobre o qual você pode saber se está chegando mais perto, ou se dele está se afastando. Mas não há nenhuma maneira de sabermos quão distantes estamos da Verdade, nem mesmo se estamos mais perto dela que nossos ancestrais. Pois, mais uma vez, o único critério que temos para aplicar à palavra "verdadeiro" é a justificação, e a justificação 
é sempre relativa a uma audiência. Assim, é também relativa à perspectiva dessa audiência - aos propósitos que tal audiência quer consumar e à situação na qual ela se encontra. (RORTY: 1998, p.18-9)

Assim, o fazer científico seria a simples capacidade de se fazer predições e solucionar problemas. Rorty sugere que ao invés de nos preocuparmos tanto com as verdades que desconhecemos, poderíamos explorar a existência ou não de formas de falar e agir desconhecidas por nós e talvez até melhores. Ele afirma que isso mudaria nossa perspectiva tão centrada na objetividade, substituindo-a por algo mais eficaz.

Conforme o desenvolvimento de novas pesquisas nesta área, acredito que obteremos não 'a resposta definitiva', mas pistas cada vez mais nítidas em direção ao conhecimento. O perigo para quem não quer correr o risco é de que estas mesmas pistas venham a contradizer tudo o que já foi cientificamente 'provado', evidenciado por teorias ou intuitamente vivenciado.

\section{Algumas conseqüências do mito do objetivismo para o discurso}

Como pôde-se observar nos itens anteriores, o mito do objetivismo há muito enraizou-se em nossa cultura. A tradição objetivista na filosofia ocidental é conservada até os dias atuais. Isto pode ser facilmente observado nos diversos âmbitos da ciência, tecnologia, do governo, jornalismo, da economia e etc. Conforme Lakoff e Johnson, a grande maioria dos ilustres filósofos e lingüistas objetivistas consideram que: "A verdade é uma questão de correspondência entre palavras e mundo. O sentido é objetivo e não corporificado, independente da compreensão humana" (LAKOFF e JOHNSON: 2002, p. 306-7).

Porém, para Lakoff e Johnson o sentido não é objetivo ou descorporificado, mas baseado na aquisição e uso de um sistema conceptual. Assim, a verdade brota desse sistema e das metáforas que o estruturam. 
Portanto, entende-se que a verdade não pode ser absoluta ou objetiva, mas fundamentada na compreensão. Conseqüentemente, nem as frases e palavras possuem sentidos fixos em si mesmas nem a comunicação pode ser confundida como mera transmissão. Talvez por esta razão, ou seja, da metáfora desvelar o poderoso mito do objetivismo é que a linguagem figurada seja tão refutada pelos clássicos filósofos e lingüistas em sua maioria.

Segundo a tradição objetivista, as convenções da língua percebem cada frase como se possuíssem um sentido próprio, objetivo, verdadeiro e independente da compreensão de uma determinada pessoa. Assim, a mesma frase emitida por uma pessoa ou por um papagaio seria idêntica. O que importa é a compreensão das condições sob as quais a frase seria verdadeira ou falsa. Então, de acordo com esta visão, não existe sentido para alguém, já que o sentido é algo independente daquilo que os seres humanos fazem, ou da maneira como fazem. Um exemplo disso é a visão objetivista em relação à semântica. Eles a consideram como um estudo da maneira que as expressões lingüísticas podem corresponder ao mundo sem qualquer interferência da compreensão humana. O lema de Richard Montague seria: 'corresponder as palavras ao mundo, sem considerar pessoas ou compreensão humana' (In LAKOFF e JOHNSON: 2002, p.311).

Já que a compreensão humana se dá desta forma, uma língua pode criar convenções de acordo com os sentidos (objetivos) atribuídos a frases. Dessa maneira, Lakoff e Johnson explicam: "na abordagem objetivista, as convenções que uma língua possui para emparelhar frases com sentidos objetivos dependerão da capacidade de os falantes dessa língua compreenderem as frases como tendo esse sentido objetivo" (LAKOFF e JOHNSON: 2002, p.309).

Normalmente essa noção de compreensão restringe-se à idéia de 
verdadeiro e falso.

A concepção de uma verdade objetiva cria a possibilidade de se formular uma teoria do sentido objetivo. Sob essa concepção, de acordo com o caso, uma frase pode ser reconhecida como verdadeira ou falsa. A técnica de Lakoff e Lewis (in Lakoff e Johnson, 2002) utiliza esta noção de verdade de acordo com a 'correspondência com o mundo'. Ainda de acordo com esses pressupostos, as noções de "verdade" ou "falsidade" são vistas em termos de condições de satisfação, incluindo neste caso os atos de fala e declarações.

Outro aspecto a ser considerado de acordo com o mito do objetivismo é a constituição do mundo por objetos. Estes são visto com bem definidos e com propriedades inerentes precisas. Acredita-se que há relações fixas entre essas propriedades em um certo período de tempo. Assim, pode-se atribuir nomes aos objetos precisamente correspondentes a essas relações. Também a sintaxe é assim compreendida pelos objetivistas:

O sentido da frase inteira dependerá completamente dos sentidos de suas partes e do modo como elas juntas se ajustam. $\mathrm{O}$ sentido das partes especificará que nomes podem designar que objetos e que predicados podem designar que propriedades e relações. (LAKOFF e JOHNSON: 2002, p. 314)

Os autores explicam que seria como se, para o objetivista, o mundo fosse feito de blocos para construção, ou seja, de objetos que podemos definir, sendo suas propriedades e relações bem delimitadas e óbvias. Tudo o que se acresce a esse sistema seria desnecessário.

Por outro lado, Quine (In LAKOFF e JOHNSON, 2002) argumenta que toda língua tem sua ontologia própria e que, portanto, as noções de objeto, propriedade e relação variam de língua para língua. Conhecida como a tese da 'relatividade ontológica', essa posição afirma que cada língua absorve o mundo diferentemente através da seleção de objetos, propriedades e relações disponíveis em sua realidade. Portanto, 
verdades de uma língua são dificilmente traduzidas em outra. Contudo, esta tese continua a se igualar ao mito objetivista na questão da existência da 'verdade' e do sentido objetivo, o qual exclui qualquer forma de compreensão humana.

Retomando-se a questão dos objetos, segundo o mito do objetivismo, pode-se afirmar que palavras e frases podem ser manuseadas como objetos. Elas têm propriedade em e por si mesmas, as quais têm relações fixas umas com as outras, independentemente do falante/ouvinte. Elas têm partes: raízes, prefixos, sufixos, infixos. As frases são compostas de palavras e os discursos de frases. O estudo de toda essa estrutura e suas propriedades é o que chamamos de gramática.

No caso da gramática, os objetos lingüísticos também são independentes do contexto e da compreensão humana. Noam Chomsky compartilha desta visão e sustenta que a gramática é uma questão de 'pura forma', já que qualquer aspecto da linguagem que se relacione à compreensão humana é excluído neste tipo de estudo.

A visão dos sentidos e expressões lingüísticas como objetos deu origem a teoria objetivista da comunicação, à qual se assemelha a metáfora do canal, que subentende: "Sentidos são objetos. Expressões lingüísticas são objetos. Expressões lingüísticas têm sentidos (em si). Na comunicação, o falante envia um sentido fixo para o ouvinte, via expressão lingüística associada a esse sentido". (LAKOFF e JOHNSON: 2002, p.318)

Dessa maneira, as eventuais falhas na comunicação são consideradas enganos puramente subjetivos, pois os sentidos são explícitos. No caso em que uma pessoa compreenda um enunciado em um determinado contexto, diferentemente do literal, este sentido é chamado pelos objetivistas de 'sentido do falante ou enunciador'. Assim, uma determinada frase pode ser objetivamente 'falsa' ou 'verdadeira' de acordo com o contexto.

Isso se aplica também aos casos de sarcasmo, eufemismo, ironia e 
em particular ao caso da metáfora. O sentido objetivo literal nestes casos seria considerado falso, mas teria um sentido pretendido pelo falante $\mathrm{X}$ que pode ser verdadeiro. Portanto, para a compreensão da linguagem figurada deve-se, de acordo com essa visão, fazer uso da compreensão indiretamente, já que este tipo de linguagem transmite um sentido objetivo diferente do sentido literal. A compreensão indireta leva em consideração o momento que o falante utiliza uma frase para transmitir um sentido indireto.

Resumindo, não há lugar para metáforas no objetivismo, já que os sentidos são sempre objetivos, expressando condições de verdade. A linguagem figurada pode, no máximo, ser um instrumento de como se expressar indiretamente.

Entretanto, Lakoff e Johnson argumentam, fundamentados nas evidências lingüísticas, que a filosofia objetivista não explica como a compreensão da nossa experiência, nossos pensamentos e linguagem se dá. Para eles, uma adequada explicação deveria requerer que:

Consideremos os objetos somente como entidades relativas às nossas interações com o mundo e às nossas projeções sobre ele;

Consideremos as propriedades como interacionais ao invés de inerentes;

Consideremos as categorias como gestalts experienciais definidas via protótipo, ao invés de considerá-las como rigidamente fixadas e definidas via uma teoria estabelecida. (LAKOFF e JOHNSON: 2002, p.323)

Ainda para eles, os problemas em relação ao sentido nas línguas naturais e à forma que as pessoas compreendem sua língua e suas experiências são problemas empíricos e não filosóficos. Pode-se resumir concluindo que, para os autores em pauta, os argumentos da visão objetivista são inadequados pois estão calcados em assunções errôneas.

Haja vista que as explicações objetivistas precisam de propriedades inerentes e que a grande parte destas requer uma categorização, elas 
não conseguem explicar a maneira que nós seres humanos conceptualizamos o mundo. O que os objetivistas não aceitam é que o mundo não é um universo objetivista, principalmente no que se refere à experiência, linguagem humana, e ao sistema conceptual humano. Contudo, não se pode afirmar que os modelos objetivistas são inúteis. Certamente eles têm também uma função nas ciências humanas.

As abordagens e pressupostos aqui são de extrema complexidade e seria incorreto afirmar que qualquer uma delas seja coerente com a verdade e a realidade em que vivemos. Há ainda um longo caminho a ser percorrido na 'viagem' de nossas vidas. No entanto, é importante ressaltar que o fundamental é observar o quanto os binômios falso/verdadeiro, objetivo/subjetivo, imaginação/realidade, razão/emoção há muito têm sido alvo de discussões e revisões, e certamente continuarão a ser.

\section{5. Últimas considerações}

$\mathrm{Na}$ vida, principalmente nos dias atuais, temos a sensação de que nada se conclui. Como já dizia Sócrates, o velho lema "Só sei que nada sei" continua e continuará a ser parte de nossas vidas infinitamente. Pois na verdade, o homem nada sabe de si mesmo ou de seu semelhante. Todavia, há que se acreditar na eterna utopia do tentar, agir, ainda que não se tenha certeza alguma do resultado. O que importa de fato é a existência do produzir, do fazer.

Este artigo não tem a intenção de meramente criticar e/ou trazer soluções definitivas quanto ao mito do objetivismo. De certo, ele não se pretende conclusivo. Entretanto, se ao menos trouxe à tona questões tão complexas e presentes em nosso meio, e provocou uma necessidade de questionamento por parte de quem sabe que não se pode ser depositário de verdades definitivas, compreendendo portanto, que o essencial é a busca e o respeito às diferentes visões, possivelmente cumpriu o seu 
papel, ainda que temporariamente. Pois, como diz Coracini, "cada leitor, com a sua experiência, sua vida, sua reflexão, acrescentará à tessitura, sempre inacabada... novos fios, novos sentidos, novos suplementos..." (CORACINI: 1999, p.14).

\section{Referências}

ALMEIDA, C. L. O que é epistemologia. In: Revista de Educação AEC. n 102. 1997. CERDERA, Cristiane Pereira. O Discurso da Ciência e a Construção do Real. Dissertação de Mestrado. Niterói: UFF, 2002.

CHAUÍ, M. Convite à Filosofia. São Paulo: Ática, 1999.

CORACINI, M. J. R. F. Interpretação, Autoria e Legitimação do Livro Didático.

Campinas: Pontes, 1999.

DEMO, P. Pesquisa e Informação Qualitativa. São Paulo: Papirus, 2001.

GELLNER, E. Razão e Cultura. Lisboa: Teorema, 1992.

HESSEN, J. Teoria do Conhecimento. São Paulo: Martins Fontes, 2000.

LAKOFF, G. e JOHNSON, M. Metáforas da Vida Cotidiana. Tradução do Grupo de Estudos da Indeterminação e da Metáfora (GEIM). Campinas; São Paulo: Mercado das Letras; EDUC, 2002.

ORTONY, A. (Ed.) Metaphor and Thought. Cambridge: Cambridge University Press, 1993.

PETERS, M. Pós-estruturalismo e Filosofia da Diferença. Belo Horizonte: Autêntica, 2000.

RORTY, R. Pragmatismo, filosofia analítica e ciência. In: PINTO, P. R. et al. Filosofia Analítica, Pragmatismo e Ciência. Belo Horizonte: Ed. UFMG, 1998.

VICO, G. A Ciência Nova. Tradução, prefácio e notas de Marco Lucchesi. Rio de Janeiro: Record, 1999. 